\title{
Supply chain production model with preservation technology under fuzzy environment
}

\author{
S.R. Singh ${ }^{a}$ and Vandana Gupta ${ }^{b^{*}}$
}

${ }^{a}$ Department of Mathematics, D.N. (P.G) College, Meerut 250001, Uttar Pradesh, India ${ }^{b}$ Research scholar, Banasthali University, India

\section{CHR ON I C L E ABSTRACT}

Article history:

Received September 22013

Received in Revised Format

November 172013

Accepted March 202014

Available online

March 252014

Keywords:

Single producer

Single supplier

Preservation technology

Partial backlogging

Fuzzy demand and fuzzy

production
In this paper, an attempt is made to characterize the preservation technology for deteriorating items to reduce the deterioration rate. This model assumes a single producer and single supplier and formulates a production model with a time varying rate of deterioration rate. Here production and demand are treated as a fuzzy variables and total cost is minimized for both the crisp and fuzzy model. Shortage is allowed on the supplier's part, which is partially backlogged. A solution procedure is presented to determine an optimal replenishment cycle and total cost per unit time, which is a convex function of preservation technology cost. Results have been validated with relevant example. In a way, the proposed model provides a unique theory to reduce the deterioration rate for the production model.

\section{Introduction}

Deteriorating inventory were studied in the past decades (Ghare \& Schrader, 1963; Covert \& Philip, 1973; Dave \& Patel, 1981; Kang \& Kim, 1983; Goyal \& Giri, 2001; Bhunia et al., 2009; Chang et al. 2010; Singh \& Singh, 2011) and the focus was usually on constant or variable deterioration rate and quantity discount. Investing on preservation technology (PT) for reducing deterioration rate has received little attention in the past years. The consideration of PT is important due to rapid social changes and the fact that PT can reduce the deterioration rate, significantly. Moreover, sales, inventory and order quantities are very sensitive to the rate of deterioration, especially for fast deteriorating products. The higher rate of deterioration would result in a higher total annual relevant cost and a lower demand rate (Yang \& Wee, 2006; Johnny et al., 2007). Ouyang et al. (2006) found that if the retailer can reduce effectively the deteriorating rate of items by improving the storage facility then the total annual relevant inventory cost could be reduced. Many enterprises invest on equipment to reduce the deterioration rate and extend the product expiration date. For example, refrigeration equipment is used

* Corresponding author

E-mail: vandana.vandana1983@gmail.com (V.Gupta)

(C) 2014 Growing Science Ltd. All rights reserved.

doi: $10.5267 /$ j.ijiec. 2014.3 .002 
to reduce the deterioration rate of fruits, flowers and sea foods in the supermarket. Murr and Morris (1975) showed that a lower temperature could increase the storage life and decrease decay. Wee et al. (2010) presented a model using PT. Huang et al. (2011) discussed the comments on PT investment for deteriorating inventory. Dye and Hsieh (2012) developed an optimal replenishment policy for deteriorating items with effective investment in PT. Dye (2013) investigated on the effect of PT investment on a non-instantaneous deteriorating inventory model. Hsieh and Dye (2013) developed a production inventory model incorporating the effect of PT investment when demand is fluctuating with time.

Generally, some customers would like to wait for backlogging during the shortage period. However, the willingness is diminished with the length of the waiting time for the next replenishment. The longer the waiting time is, the smaller the backlogging rate is. The opportunity cost due to lost sales should be considered. Papachristos and Skouri (2000) developed an EOQ inventory model with time-dependent partial backlogging. They assumed the rate of backlogged demand increases exponentially while the waiting time for the next replenishment decreases. Teng et al. (2003) extended the backlogged demand to any decreasing function of the waiting time up to the next replenishment. The related analysis on inventory systems with partial backlogging have been performed by Teng and Yang (2004), San José et al. (2006), Chang and Lin (2010), etc.

Usually researchers consider different parameters of an inventory model either as constant, timedependent or probabilistic nature for the development of the economic order quantity model. However, in the real life situations, these parameters may have little deviations from the exact value, which may not follow any probability distribution. In these situations, if these parameters are treated as fuzzy parameters, then it will be more realistic. These types of problems are de-fuzzified by using a suitable fuzzy technique and then the solution procedure can be obtained in the usual manner. Several authors, namely Chang et al. (2010), Lin and Yao (2000), Singh and Singh (2011), Ruoning and Xiaoyan (2010) and Singh et al. (2011) developed inventory models in fuzzy sense by considering different parameters in fuzzy sense. Yadav et al. (2013) focused on retailer's optimal policy under inflation in fuzzy environment with trade credit. Urvashi and Singh (2013) discussed a model of inventory control with fuzzy inflation and volume flexibility under random planning horizon. Dutta and Kumar (2013) discussed about the fuzzy inventory models for deteriorating items with shortages and fully backlogged condition.

In this research, an effort is accomplished to formulate a supply chain production model for deteriorating items with fuzzy demand, fuzzy production by allowing preservation technology cost. Under real life circumstances, these parameters in the production model are uncertain and imprecise. In this situation, a suitable way to model these imprecise data is to use fuzzy sets and to formulate a production model in a fuzzy environment. We use the centroid method for defuzzifying fuzzy total average cost. For the proposed model, producer and supplier use the preservation technology. The optimal solution of the proposed model not only exists but also is unique. To illustrate the theory of the proposed model, a numerical example is provided and sensitivity analysis with respect to parameters of the system is carried out in both crisp and fuzzy sense.

\section{Assumptions and Notation}

In developing the mathematical models of the inventory system for this study, the following common assumptions were used.

1) This study considered single producer and single supplier.

2) Multiple deliveries per order are considered.

3) Production rate is finite and of constant rate.

4) Demand rate is constant. 
5) Reduced deterioration rate, a function of $\zeta$ such that $\mathrm{m}(\zeta)=\mathrm{k}\left(1-\mathrm{e}^{-\mathrm{a} \zeta}\right), \mathrm{a} \geq 0$, where a is the simulation coefficient representing the percentage increase in $\mathrm{m}(\zeta)$ per dollar increase in $\zeta, \mathrm{k}$ is the original deterioration rate, $\mathrm{k}>0$ and $\zeta$ is the Preservation technology cost for reducing deterioration rate in order to preserve the products, $\zeta \geq 0$.

6) For producer and supplier PT cost is $\zeta$ and $\eta$, respectively.

7) Shortages are allowed on the supplier's part. Unsatisfied demand is partially backlogged. The fraction of shortages backordered is a differentiable and decreasing function of time $t$, denoted by $\delta(t)$, where $t$ is the waiting time up to the next replenishment, and $0 \leq \delta(t) \leq 1$ with $\delta(0)=1$. Note that if $\delta(t)=1$ (or 0 ) for all $t$, then shortages are completely backlogged (or lost).

The following common notations were used.

$\mathrm{T}$ the length of the inventory cycle

d the demand rate

$\mathrm{A}_{\mathrm{p}} \quad$ the ordering cost per order for producer

$\mathrm{C}_{\mathrm{p}}$ the unit purchasing cost for producer

$\mathrm{h}_{\mathrm{p}}$ the unit holding cost per order

$I_{p 1}(t)$ the level of inventory at time $t$ for producer during $0<t<T_{1}$

$I_{p 2}(t)$ the level of inventory at time $t$ for producer during $0<t<T_{2}$

$\mathrm{I}_{\mathrm{mp}}$ the maximum inventory for Producer

$\mathrm{T}_{1}$ the length of production time for producer (a decision variable)

$\mathrm{T}_{2}$ the length of non-production time

$\mathrm{p}$ the production rate

$\mathrm{I}_{\mathrm{s} 1}(\mathrm{t})$ the level of inventory at time $\mathrm{t}$ for supplier during $0<\mathrm{t}<\mathrm{T}_{3}$

$\mathrm{I}_{\mathrm{s} 2}(\mathrm{t})$ the level of inventory at time $\mathrm{t}$ for supplier during $0<\mathrm{t}<\mathrm{T}_{4}$

$\mathrm{T}_{3}$ the length of inventory cycle for supplier (a decision variable)

$\mathrm{T}_{4}$ the length of shortage time for supplier

$\mathrm{I}_{\mathrm{ms}}$ the level of maximum inventory for supplier

$\mathrm{h}_{\mathrm{s}} \quad$ the unit holding cost per order for supplier

$\mathrm{A}_{\mathrm{s}} \quad$ the set up cost per order for Supplier

$\mathrm{C}_{\mathrm{s}}$ the unit purchasing cost for the supplier

$\mathrm{Cs}_{1}$ the backlogging cost per unit

$\mathrm{C}_{\mathrm{s} 2}$ the lost sale cost per unit

$\delta$ the backlogging rate

$\mathrm{n} \quad$ the number of cycles

$\mathrm{k}$ the original deterioration rate

$\zeta \quad$ the PT cost for producer

$\eta \quad$ the PT cost for supplier

TC the integrated cost of producer and supplier

\section{Model development for producer}

The inventory model is shown in Fig. 1 . The planning horizon $\mathrm{T}$ is divided by 2 parts $\mathrm{T}_{1}$ and $\mathrm{T}_{2}$, where $\mathrm{T}_{1}$ is the production time and $\mathrm{T}_{2}$ is the non-production time. During the time interval $\left[0, \mathrm{~T}_{1}\right]$, the inventory level decreases due to demand and deterioration and increases due to the production. During the time interval $\left[0, \mathrm{~T}_{2}\right]$, there is no production, the inventory decreases due to deterioration rate and demand. This figure also shows that if we use the PT then our production is more and we can use our stock for a long time period. 
Inventory level

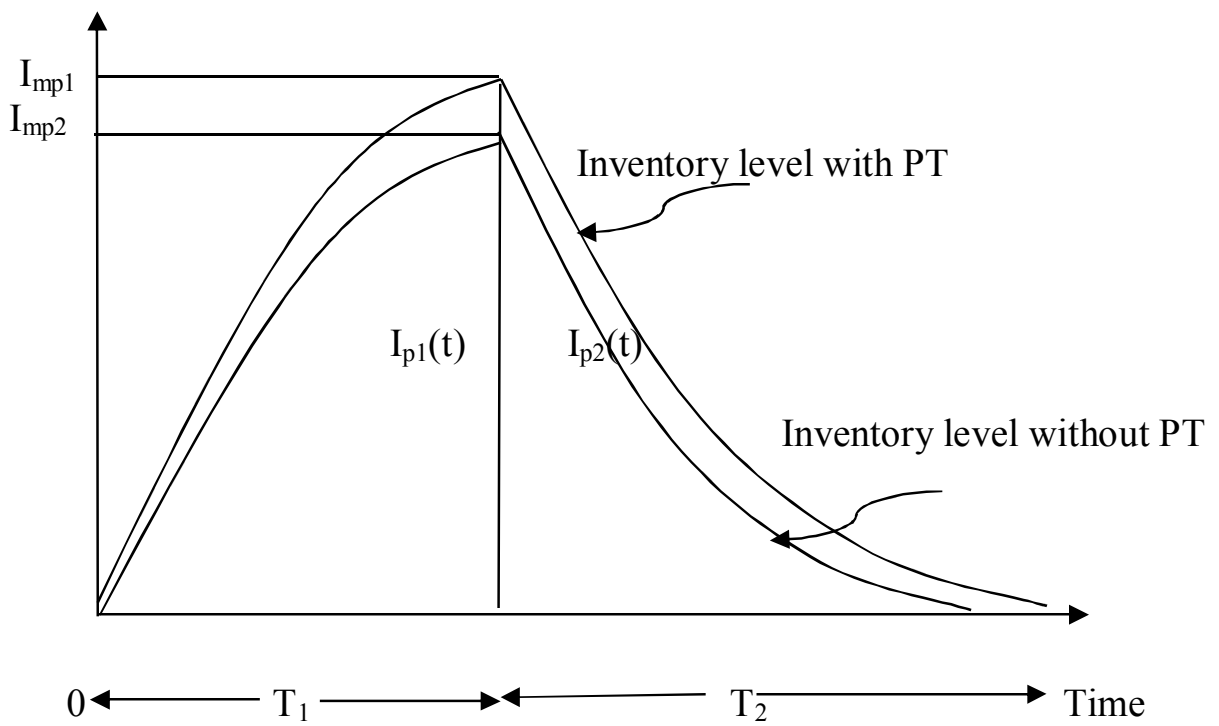

Fig. 1. The graphic representation of inventory model for producer

There are the following differential equations for the inventory level of producer.

$I_{p 1}^{\prime}(t)=p-d-[k-m(\varsigma)] I_{p 1}(t), \quad 0 \leq t \leq T_{1}$

$I_{p_{2}}^{\prime}(t)=-d-[k-m(\varsigma)] I_{p 2}(t), \quad 0 \leq t \leq T_{2}$

We have boundary conditions $I_{p 1}(0)=0$ and $I_{p_{2}}\left(T_{2}\right)=0$, the solution of the above differential equations are as follows,

$$
\begin{array}{ll}
I_{p 1}(t)=\frac{(p-d)}{k-m(\varsigma)}\left[1-e^{[m(\varsigma)-k] t}\right] & 0 \leq t \leq T_{1} \\
I_{p 2}(t)=\frac{d}{k-m(\varsigma)}\left[e^{-[k-m(\varsigma)]\left(t-T_{2}\right)}-1\right] & 0 \leq t \leq T_{2}
\end{array}
$$

By the boundary condition $\mathrm{I}_{\mathrm{p} 1}\left(\mathrm{~T}_{1}\right)=\mathrm{I}_{\mathrm{p} 2}(0)$, we have

$$
\begin{aligned}
& \frac{(p-d)}{k-m(\varsigma)}\left[1-e^{-[k-m(\varsigma)] T_{1}}\right]=\frac{d}{k-m(\varsigma)}\left[e^{[k-m(\varsigma)] T_{2}}-1\right] \\
& T_{2}=\frac{p-d}{d}\left[T_{1}-\frac{(k-m(\varsigma)) T_{1}^{2}}{2}\right] \\
& T=T_{1}+T_{2}=T_{1}+\frac{p-d}{d}\left[T_{1}-\frac{(k-m(\varsigma)) T_{1}^{2}}{2}\right]
\end{aligned}
$$

By using the boundary condition $I_{m p}=I_{p 2}(0)$, we can find out the maximum inventory level with PT and without PT, which is as follows,

$$
I_{m p 1}=\frac{d}{k-m(\varsigma)}\left[e^{[k-m(\varsigma)] T_{2}}-1\right]
$$


and

$$
I_{m p 2}=\frac{d}{k}\left[e^{k T_{2}}-1\right] \text {. }
$$

The total relevant cost involves the following four factors,

(a). Holding cost: The present value of the holding cost per unit time is as follows,

$$
\begin{aligned}
H C_{p}= & \frac{h_{p}}{T}\left[\int_{0}^{T_{1}} I_{p 1}(t) e^{-r t} d t+e^{-r T_{1}} \int_{0}^{T_{2}} I_{p 2}(t) e^{-r t} d t\right] \\
& =\frac{h_{p}}{T}\left[-\frac{(p-d)}{k-m(\varsigma)}\left\{\frac{1-e^{-[k-m(\varsigma)+r] T_{1}}}{k-m(\varsigma)+r}+\frac{e^{-r T_{1}}-1}{r}\right\}-\frac{d e^{-r T_{1}}}{k-m(\varsigma)}\left\{\frac{1-e^{-r T_{2}}}{r}-\frac{e^{[k-m(\varsigma)] T_{2}}-e^{-r T_{2}}}{k-m(\varsigma)+r}\right\}\right]
\end{aligned}
$$

(b). Purchasing cost: The purchasing cost includes loss due to deterioration as well as the cost of the item. The present value of the purchasing cost per unit time is as follows,

$I C_{p}=\frac{c_{p}}{T} P T_{1}$

(c). Ordering cost: The present value of the ordering cost per unit time is as follows,

$S C_{p}=\frac{A_{p}}{T}$

(d). Preservation Technology cost per unit time is

$P C_{p}=\frac{\varsigma}{T}$

Hence, the present value of the total relevant inventory cost per unit time is as follows,

$$
\begin{aligned}
T C_{p}= & H C_{P}+I C_{P}+S C_{P}+P C_{p} \\
& =\frac{1}{T}\left[h_{p}\left\{\begin{array}{l}
-\frac{(p-d)}{k-m(\varsigma)}\left\{\frac{1-e^{-[k-m(\varsigma)+r] T_{1}}}{k-m(\varsigma)+r}+\frac{e^{-r T_{1}}-1}{r}\right\} \\
-\frac{d e^{-r T_{1}}}{k-m(\varsigma)}\left\{\frac{1-e^{-r T_{2}}}{r}-\frac{e^{[k-m(\varsigma)] T_{2}}-e^{-r T_{2}}}{k-m(\varsigma)+r}\right\}
\end{array}\right\}+c_{p} P T_{1}+A_{p}+\varsigma\right]
\end{aligned}
$$

\section{Model development for supplier}

The inventory model is shown in Fig.2. The planning horizon $T / n$ is divided in 2 parts of $T_{3}$ and $T_{4}$, where $T_{4}$ is the shortage time. Supplier's cycle starts with the maximum inventory $I_{m s}$ at $t=0$. During the time interval $\left[0, T_{3}\right]$, the inventory level decreases due to demand and deterioration with PT. During the time interval $\left[0, T_{4}\right]$, shortage occurs, which is partial backlogged. The inventory level at time $t$ during the time interval $\left[0, T_{3}\right]$, and $\left[0, T_{4}\right]$, is governed by the following differential equations, 
$I_{s 1}{ }^{\prime}(t)=-d-[k-m(\eta)] I_{s 1}(t)$,

$$
\begin{aligned}
0 & \leq t \leq T_{3} \\
0 \leq t & \leq T_{4}
\end{aligned}
$$$$
I_{s 2}{ }^{\prime}(t)=-\delta d
$$

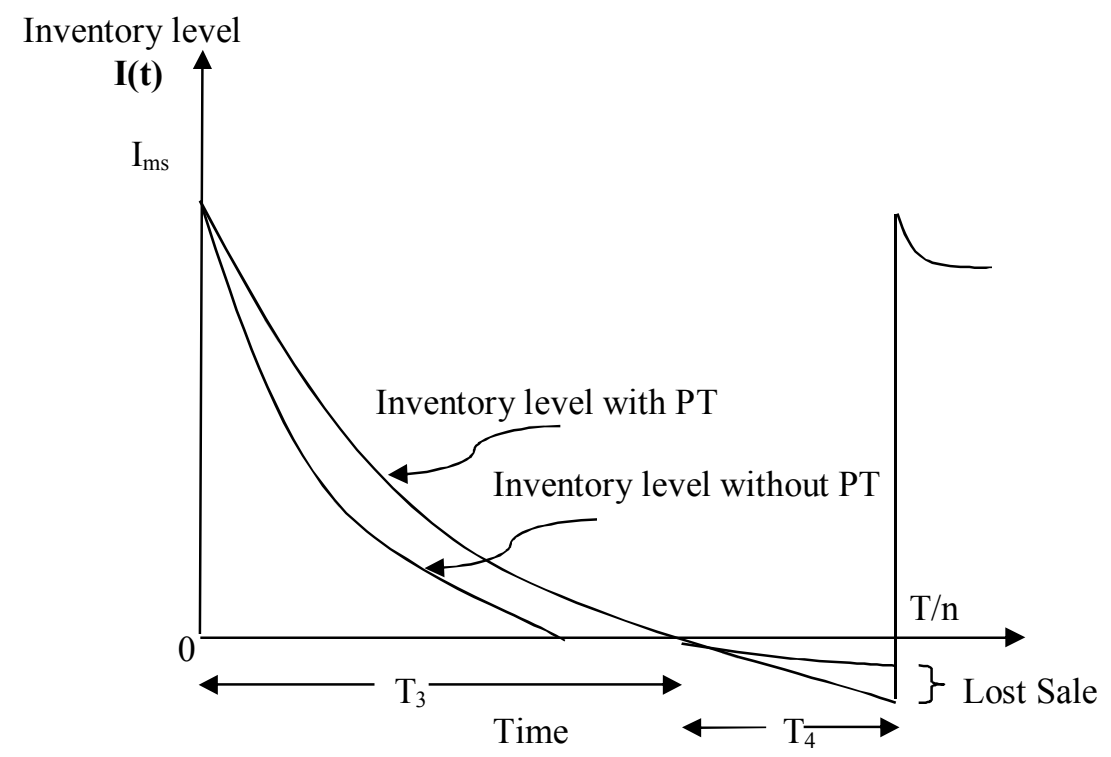

Fig. 2. The graphic representation of inventory model for supplier

With the boundary condition $I_{s 1}\left(T_{3}\right)=0$ and $I_{s 2}(0)=0$, the solution of the above differential equations are as follows,

$$
\begin{aligned}
& I_{s 1}(t)=\frac{d}{k-m(\eta)}\left[e^{-[k-m(\eta)]\left(t-T_{3}\right)}-1\right] \\
& I_{s 2}(t)=-\delta d t
\end{aligned}
$$

By using the condition $I_{m s}=I_{s}(0)$, we have maximum inventory for the supplier is follows,

$$
I_{m s}=\frac{d}{k-m(\eta)}\left[e^{-[k-m(\eta)] T_{3}}-1\right]
$$

The total relevant cost involves the following six factors as follows,

(a). Holding cost: The present value of the holding cost per unit time is

$$
H C_{s}=\frac{h_{s} n}{T} \int_{0}^{T_{3}} I_{s}(t) e^{-r t} d t=\frac{n h_{s} d}{(k-m(\eta)) T}\left\{\frac{e^{-r T_{3}}-1}{r}+\frac{e^{[k-m(\eta)] T_{3}}-e^{-r T_{3}}}{k-m(\eta)+r}\right\}
$$

(b). Purchasing cost: The present value of the purchasing cost per unit time is

$$
I C_{s}=\frac{n C_{s}}{T} I_{M b}=\frac{n C_{s}}{T}\left[\frac{d\left[e^{-[k-m(\eta)] T_{3}}-1\right]}{k-m(\eta)}\right]
$$

(c). Ordering cost: The present value of the ordering cost per unit time is as follows, 
$S C_{b}=\frac{n A_{s}}{T}$

(d). Preservation Technology cost

$$
P C_{s}=\frac{n \eta}{T}
$$

(e). Shortage cost: The present value of the shortage cost in the entire time horizon is as follows,

$$
\mathrm{BA}=\frac{n C_{s 1}}{T} \int_{0}^{T_{4}}-I_{s 2}(t) e^{-r\left(T_{3}+t\right)} d t=\frac{d \delta n C_{s 1} e^{-r T_{3}}}{T}\left[\frac{-e^{-r T_{4}} T_{4}}{r}+\frac{\left(1-e^{-r T_{4}}\right)}{r^{2}}\right]
$$

(f). Lost sale cost: The present value of the lost sale cost occurs during the time period 0 to $T_{4}$. During this time period, the complete shortage is $d T_{4}$ and the partial backlog is $d \delta T_{4}$. Lost sales are the difference between the complete shortage and the partial backlog. Thus, the present worth lost sale cost per unit time is as follows,

$$
L S=\frac{n C_{s 2} d}{T} \int_{0}^{T_{4}}(1-\delta) T_{4} e^{-r\left(T_{3}+t\right)} d t=\frac{C_{s 2} n d(1-\delta) e^{-r T_{3}} T_{4}\left(1-e^{-r T_{4}}\right)}{r T}
$$

Hence the present value of the total relevant inventory cost per unit time is

$$
\begin{aligned}
T C_{s}= & H C_{s}+I C_{s}+S C_{s}+P C_{s}+B A+L S \\
& =\frac{n}{T}\left[d\left\{\begin{array}{l}
\frac{h_{s}}{(k-m(\eta))}\left\{\frac{e^{-r T_{3}}-1}{r}+\frac{e^{(k-m(\eta)) T_{3}}-e^{-r T_{3}}}{k-m(\eta)+r}\right\}+\frac{C_{s}\left(e^{-[k-m(\eta)] T_{3}}-1\right)}{k-m(\eta)} \\
\left.\left.+\delta C_{s 1} e^{-r T_{3}}\left\{\frac{-e^{-r T_{4}} T_{4}}{r}+\frac{\left(1-e^{-r T_{4}}\right)}{r^{2}}\right\}+\frac{C_{s 2}(1-\delta) e^{-r T_{3}} T_{4}\left(1-e^{-r T_{4}}\right)}{r}\right\}+A_{s}+\eta\right]
\end{array}\right]\right.
\end{aligned}
$$

Therefore

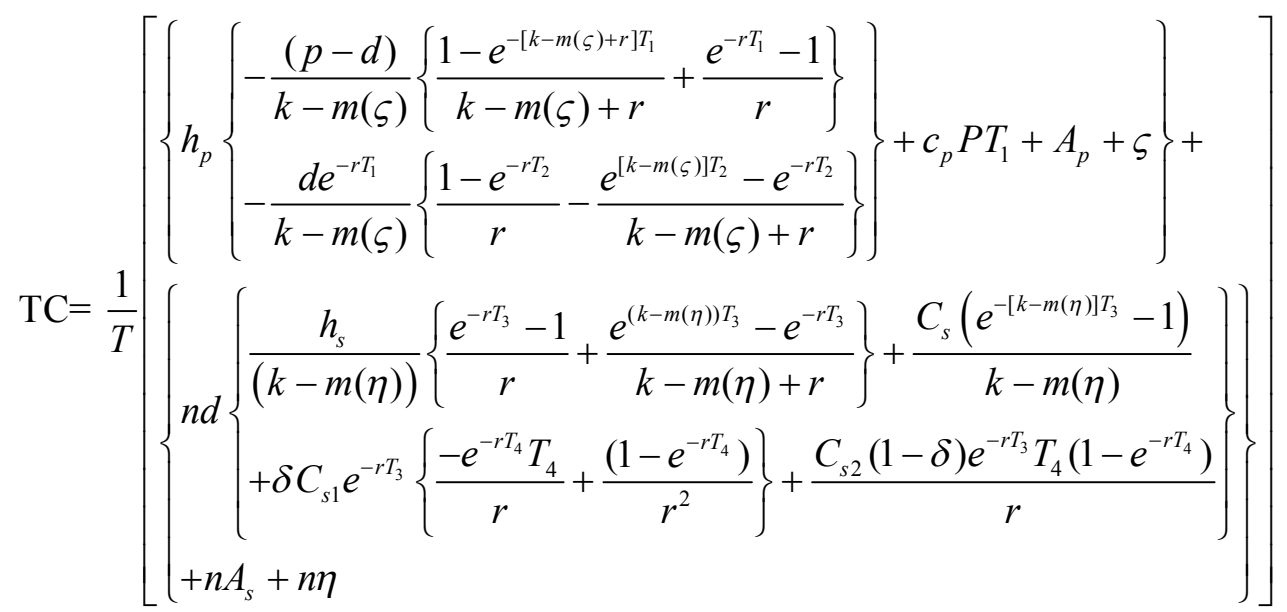

There are two decision variables in the present value of the total inventory cost $T C$. The first part is associated with the production time period of producer, $T_{l}$ and the second part is associated with the time period of supplier $T_{3}$. We can find out the value of $T_{2}$ and $T_{4}$ with the help of Eq. (5), Eq. (6) and the relation $T=T / n-T_{3}$. 


\section{Fuzzy model for producer and supplier}

In a real situation and in a competitive market situation both the production rate and the demand rate are highly uncertain in nature. To deal with such a type of uncertainties in the super market, we consider these parameters in fuzzy form. Here $p$ and $d$ are not known precisely and $p$ and $d$ are defined by triangular fuzzy numbers such that

$$
\tilde{p}=\left(p_{1}, p_{0}, p_{2}\right), \text { and } \tilde{d}=\left(d_{1}, d_{0}, d_{2}\right),
$$

where $\left(p_{0}-\Delta_{1}<p_{0}<p_{0}+\Delta_{2}\right)$ and $\left(d_{0}-\Delta_{3}<d_{0}<d_{0}+\Delta_{4}\right)$ are based on subjective judgments. We apply arithmetic operators based on fuzzy quantities and then defuzzify the same to convert them into crisp output. The membership functions for $\tilde{p}$ and $\tilde{d}$ is defined as follow,

$$
\begin{gathered}
\mu_{\tilde{p}}(p)= \begin{cases}\frac{p-p_{0}+\Delta_{1}}{\Delta_{1}}, & p_{0}-\Delta_{1} \leq p \leq p_{0} \\
\frac{p_{0}+\Delta_{2}-p}{\Delta_{2}}, & p_{0} \leq p \leq p_{0}+\Delta_{2} \\
0, & \text { otherwise }\end{cases} \\
\mu_{\tilde{d}}(d)= \begin{cases}\frac{d-d_{0}+\Delta_{3}}{\Delta_{3}}, & d_{0}-\Delta_{3} \leq d \leq d_{0} \\
\frac{d_{0}+\Delta_{4}-d}{\Delta_{4}}, & d_{0} \leq d \leq d_{0}+\Delta_{4} \\
0, & \text { otherwise }\end{cases}
\end{gathered}
$$

Here, $0<\Delta_{1}<p_{0}, 0<\Delta_{2}, 0<\Delta_{3}<d_{0}, 0<\Delta_{4}$ and $p_{0}, d_{0}$ are given fixed numbers. $\Delta_{1}, \Delta_{2}, \Delta_{3}, \Delta_{4}$ are determined by the decision maker based on the uncertainty of the problem. Defuzzification of $\tilde{p}$ and $\tilde{\mathrm{d}}$ by the centroid method is given as follows,

$$
\begin{aligned}
& M_{P}=\frac{p_{0}-\Delta_{1}+p_{0}+p_{0}+\Delta_{2}}{3}=p_{0}+\frac{1}{3}\left(\Delta_{2}-\Delta_{1}\right), \\
& M_{d}=\frac{d_{0}-\Delta_{3}+d_{0}+d_{0}+\Delta_{4}}{3}=d_{0}+\frac{1}{3}\left(\Delta_{4}-\Delta_{3}\right) .
\end{aligned}
$$

We have

$$
G(p, d)=f\left(T_{1}, T_{3}\right)+p g\left(T_{1}, T_{3}\right)+d q\left(T_{1}, T_{3}\right),
$$

Where

$$
\begin{aligned}
& f\left(T_{1}, T_{3}\right)=\frac{1}{T}\left\{A_{p}+\varsigma+n\left(A_{s}+\eta\right)\right\} \\
& g\left(T_{1}, T_{3}\right)=\frac{1}{T}\left\{c_{p} T_{1}-\frac{h_{p}}{k-m(\varsigma)}\left\{\frac{1-e^{-[k-m(\varsigma)+r] T_{1}}}{k-m(\varsigma)+r}+\frac{e^{-r T_{1}}-1}{r}\right\}\right\}
\end{aligned}
$$




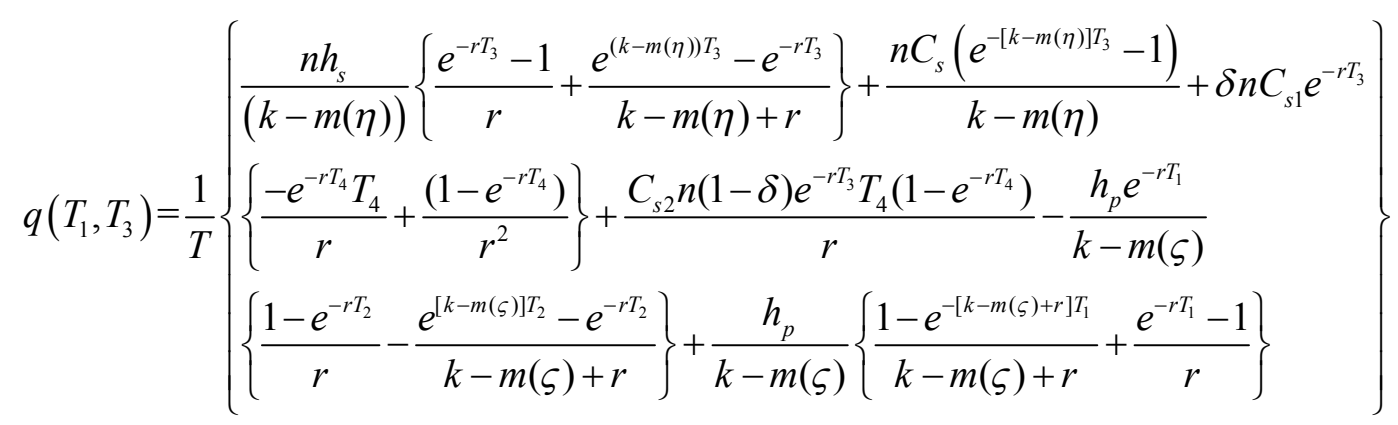

Let $\mathrm{G}(\mathrm{p}, \mathrm{d})=\mathrm{y}$, this implies that

$$
p=\frac{y-f-d q}{g} .
$$

The membership of the fuzzy cost function given by the extension principle is

$$
\mu_{\tilde{G}(\tilde{p}, \tilde{d})}(y)=\operatorname{Sup}_{(p, d) \in G^{-1}(y)}\left[\mu_{\tilde{p}}(p) \wedge \mu_{\tilde{d}}(d)\right]=\operatorname{Sup}_{\substack{d_{0}-\Delta_{3} \leq d \leq d_{0}+\Delta_{4} \\ g}}\left[\mu_{\tilde{p}}\left(\frac{y-f-d q}{g}\right) \wedge \mu_{\tilde{d}}(d)\right]
$$

Now

$$
\mu_{\tilde{p}}\left(\frac{y-f-d q}{g}\right)= \begin{cases}\frac{\left(p_{0}+\Delta_{2}\right) g-d q-f-y}{\Delta_{2} g}, & a_{2} \leq d \leq a_{0} \\ \frac{y-\left(p_{0}-\Delta_{1}\right) g-d q-f}{\Delta_{1} g}, & a_{0} \leq d \leq a_{1} \\ 0 & \text { otherwise }\end{cases}
$$

Where

$$
a_{1}=\frac{f-y+g\left(p_{0}-\Delta_{1}\right)}{q}, a_{0}=\frac{p_{0} g+f-y}{q} \text { and } a_{2}=\frac{f-y+g\left(p_{0}+\Delta_{2}\right)}{q}
$$

Defuzzification for the fuzzy total cost is thus given by centroid method is

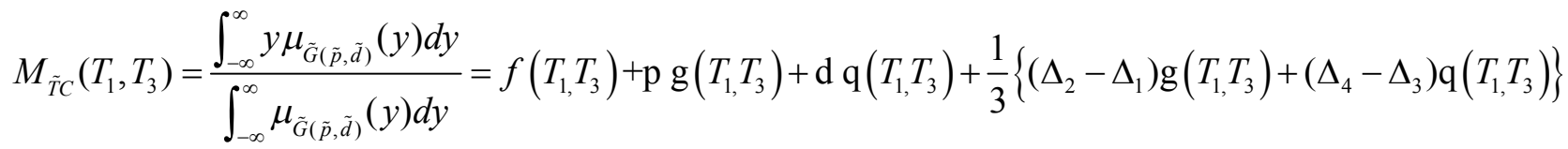

$$
\begin{aligned}
& =f\left(T_{1} T_{3}\right)+\left\{\mathrm{p}+\frac{1}{3}\left(\Delta_{2}-\Delta_{1}\right)\right\} \mathrm{g}\left(T_{1} T_{3}\right)+\left\{\mathrm{d}+\frac{1}{3}\left(\Delta_{4}-\Delta_{3}\right)\right\} \mathrm{q}\left(T_{1} T_{3}\right),
\end{aligned}
$$

where $f\left(T_{1} T_{3}\right), \mathrm{g}\left(T_{1} T_{3}\right)$ and $\mathrm{q}\left(T_{1} T_{3}\right)$ are given by Eq. (28), Eq. (29) and Eq. (30), respectively. We can minimize the total average cost per unit time for the Optimal value of $\mathrm{T}_{1}\left(\right.$ say $\mathrm{T}_{1}{ }^{*}$ ) and $\mathrm{T}_{3}\left(\right.$ say $\mathrm{T}_{3}{ }^{*}$ ) as defined above and the minimum total cost is given by $\left[M_{\tilde{T C}}\left(T_{1}, T_{3}\right)\right]$.

\section{Solution Procedure}

To derive the optimal solution, the following classical optimization technique is used. 
Step 1. Take the partial derivatives of $T C\left(T_{1}, T_{3}\right)$ with respect to $T_{1}$ and $T_{3}$ and equate the results to zero to find out the optimal value of $\mathrm{T}_{1}$ and $\mathrm{T}_{3}$. The necessary conditions for optimality are

$\frac{\partial(T C)}{\partial T_{1}}=0, \frac{\partial(T C)}{\partial T_{3}}=0$

Step 2. The convexity of the total cost is analyzed with the help of following conditions

$$
\begin{aligned}
& \frac{\partial^{2}(T C)}{\partial T_{1}^{2}} \frac{\partial^{2}(T C)}{\partial T_{3}^{2}}-\left(\frac{\partial^{2}(T C)}{\partial T_{1} \partial T_{3}}\right)^{2}>0 \\
& \text { and } \frac{\partial^{2}(T C)}{\partial T_{1}^{2}}>0
\end{aligned}
$$

Step 3. With $\mathrm{T}_{1}{ }^{*}$ and $\mathrm{T}_{3}{ }^{*}$ found in step 2 , derive $\mathrm{TC}^{*}\left(\mathrm{~T}_{1}{ }^{*}, \mathrm{~T}_{3}{ }^{*}\right)$.

\section{Numerical Example}

\subsection{Numerical illustration for crisp model}

A numerical example is considered to illustrate the model. The following values of parameters are used in this example.

$$
\begin{aligned}
& \mathrm{P}=360 \text { unit, } \mathrm{n}=2, \mathrm{~d}=350 \text { unit, } A_{p}=\$ 0.20, C_{p}=\$ 0.12, h_{p}=\$ 0.15, A_{s}=\$ 0.50, C_{s}=\$ 0.15, h_{s}=\$ 0.20, \\
& C_{s 1}=\$ 0.40, C_{s 2}=\$ 0.30, \delta=0.061, \mathrm{r}=0.001, \varsigma=\$ 200, \mathrm{k}=0.007, \eta=\$ 400, \mathrm{a}=0.001 .
\end{aligned}
$$

The software Mathematica5.2 is used to derive the optimal solution. The optimal value of total cost is obtained as $\$ 92.678$ and production time $\left(\mathrm{T}_{1}{ }^{*}\right)$ is 8.2854 days and $\left(\mathrm{T}^{*}\right)$ is 3.29462 days. With the help of Eq. (5) and Eq. (6), we can find out the non-production time period $\left(\mathrm{T}_{2}{ }^{*}\right)$ and shortage period $\left(\mathrm{T}_{4}{ }^{*}\right)$ and by using the condition of optimality we can analyze that TC is a strictly convex function, as shown below.

$$
\frac{\partial^{2}(T C)}{\partial T_{1}^{2}} \frac{\partial^{2}(T C)}{\partial T_{3}^{2}}-\left(\frac{\partial^{2}(T C)}{\partial T_{1} \partial T_{3}}\right)^{2}=30449>0 \text { and } \quad \frac{\partial^{2}(T C)}{\partial T_{1}^{2}}=1418.93>0
$$

The three dimensional producer and supplier's total cost graph is shown in Fig. 3.

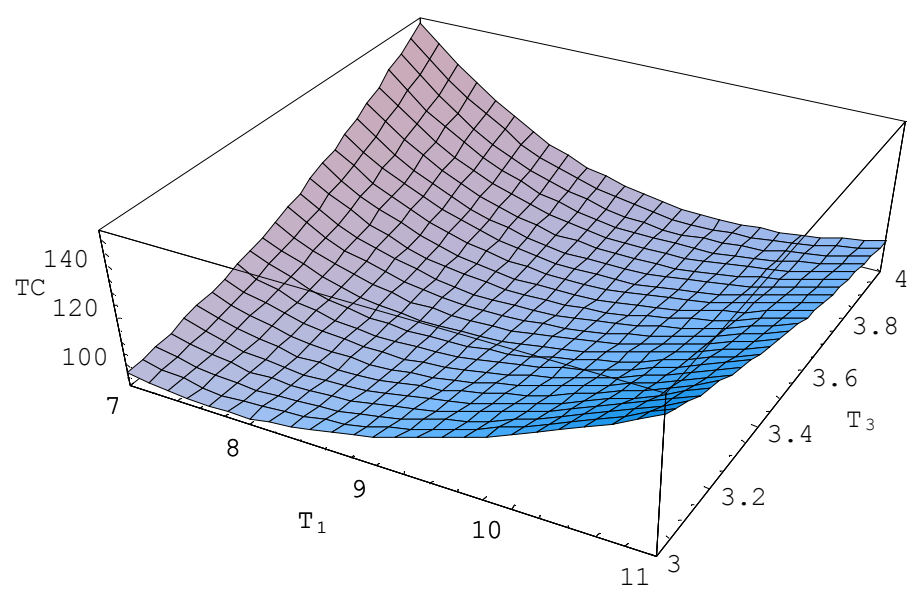

Fig. 3. The Producer and Supplier's unit time total cost in crisp model 


\subsection{Numerical illustration for fuzzy model}

All the symbols in the fuzzy environment have the same numerical values as in the crisp environment with initial demand parameter and production with some uncertainty. The production rate and demand rate are considered as the triangular fuzzy numbers $(300,360,400)$ and $(310,350,410)$, respectively

$$
\Delta_{1}=300 \quad \Delta_{2}=400 \quad \Delta_{3}=310 \quad \Delta_{4}=410 .
$$

Then optimal value of the total cost is $\$ 102.973$, production time $\left(\mathrm{T}_{1}{ }^{*}\right)$ is 7.94398 days and supplier's time $\left(\mathrm{T}_{3}{ }^{*}\right)$ is 3.16495 days. With the help of Eq. (5) and Eq. (6) we can find out the non-production time period $\left(\mathrm{T}_{2}{ }^{*}\right)$ and shortage period $\left(\mathrm{T}_{4}{ }^{*}\right)$. Total cost is more in the fuzzy environment. With the help of this data we can analyze that TC is a strictly convex function as shown as follows,

$\frac{\partial^{2}(T C)}{\partial T_{1}^{2}} \frac{\partial^{2}(T C)}{\partial T_{3}^{2}}-\left(\frac{\partial^{2}(T C)}{\partial T_{1} \partial T_{3}}\right)^{2}=706.609>0$ and $\frac{\partial^{2}(T C)}{\partial T_{1}^{2}}=12.11618>0$

The three dimensional producer and supplier's total cost graph in the fuzzy environment is shown in Fig. 4.

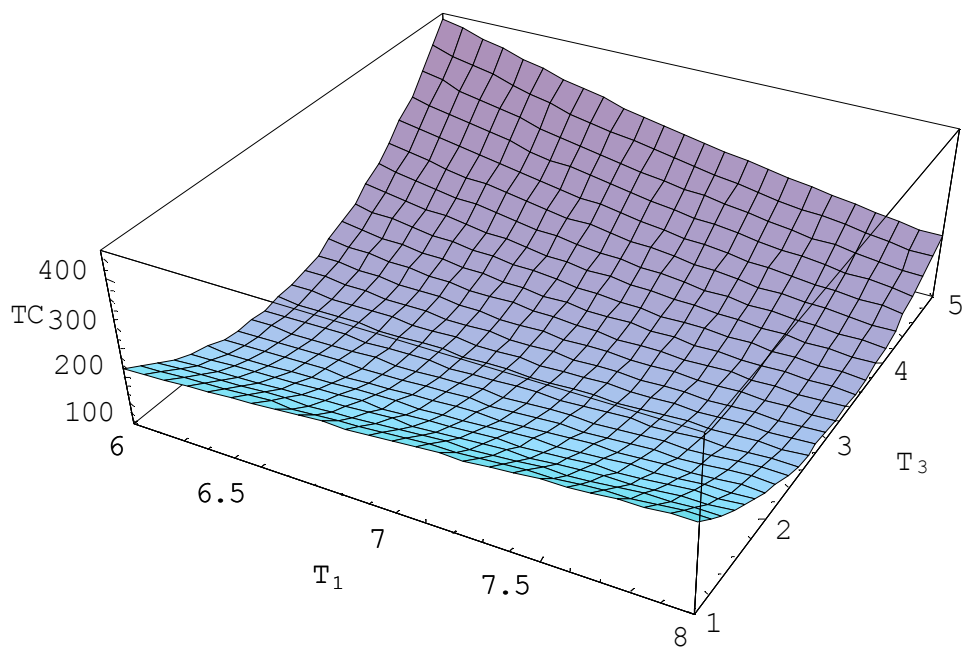

Fig. 4. The Producer and Supplier's unit time total cost in fuzzy model

\section{Sensitivity analysis}

Sensitivity analysis is carried out when the parameters $a, \zeta, \eta, n$ and $r$ are changed. Figs. 5-9 show the changes in the total cost for variables $a, n, r, \zeta$ and $k$, respectively. Fig. 5(a) and 5(b) show the changes in the total cost, while changing the value of $a$ in the crisp and fuzzy model, respectively. since $\mathrm{m}(\zeta)=$ $\mathrm{k}\left(1-\mathrm{e}^{\mathrm{a} \zeta}\right)$, where $k$ is the original deterioration rate, as $a$ increases then $\mathrm{m}(\zeta)$ is a increasing function therefore the reduced deterioration rate $(\mathrm{k}-\mathrm{m}(\zeta))$ is a decreasing function then total cost decreases. This gives a conclusion that with the PT we can reduce the deterioration rate as well as the total cost. Fig. $6(\mathrm{a})$ and $6(\mathrm{~b})$ show that as $\zeta$ (PT cost of producer) increases then the total cost decreases. Since we have less deterioration rate we have more sales and more profit. Therefore, this process is more profitable for producer. 


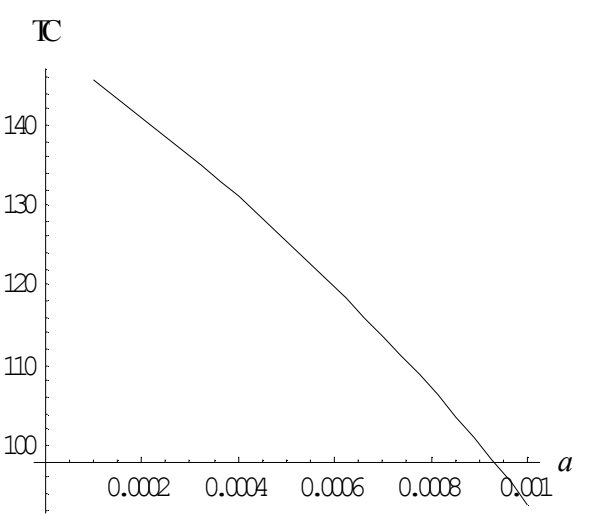

Fig. 5(a) The effect of parameter a on the total cost in the crisp model

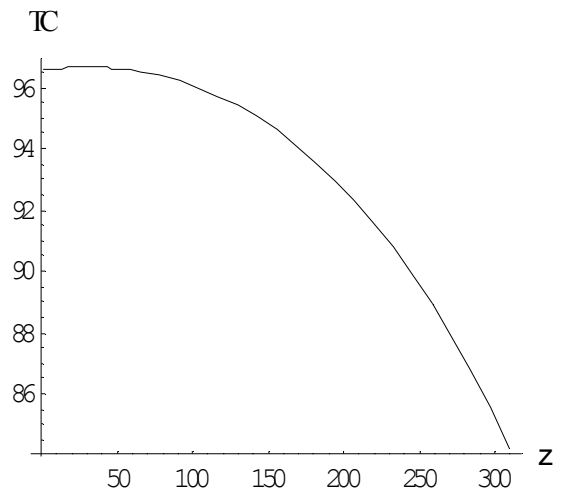

Fig.6.(a) The effect of parameter $\zeta$ on the total cost in the crisp model

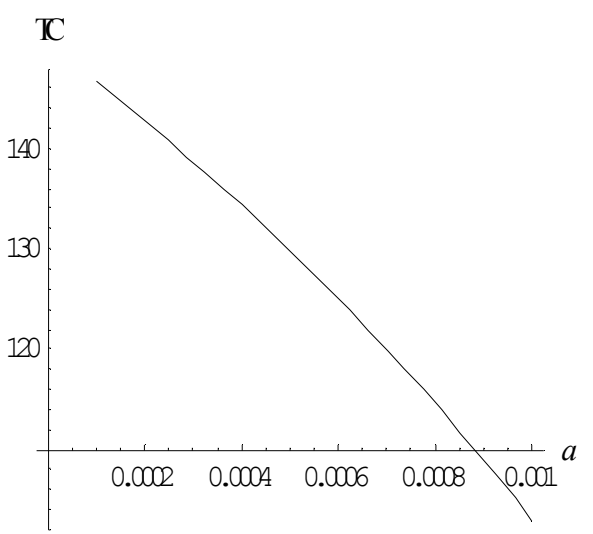

Fig. 5(b) The effect of parameter a on the total cost in the fuzzy model

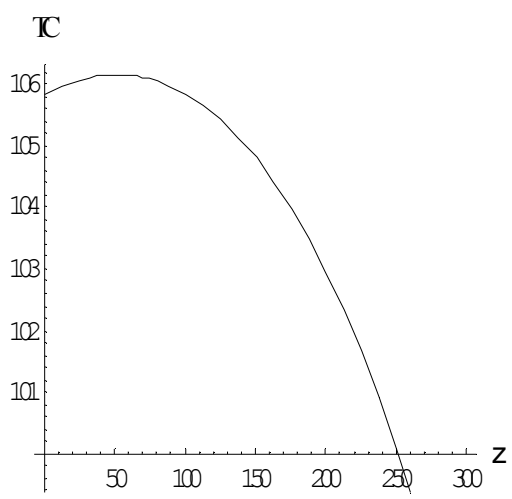

Fig.6.(b) The effect of parameter $\zeta$ on total cost in the fuzzy model

Fig. 7(a) and 7(b) show that as $\eta$ (PT cost of supplier) increases, the total cost decreases. As we have less deterioration rate then more sales and more profit. Therefore, this process is more profitable for supplier.

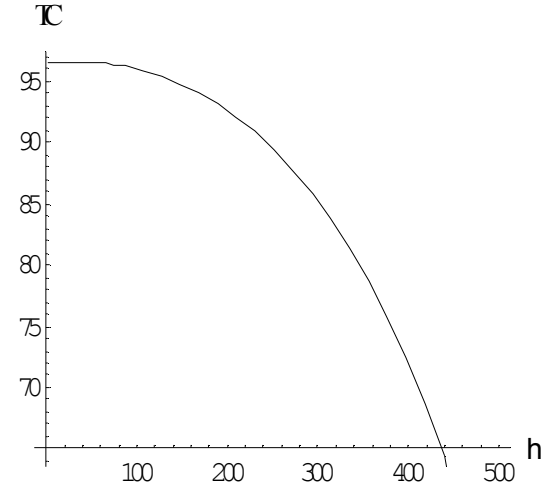

Fig 7.(a) The effect of parameter $\eta$ on the total cost in the crisp model

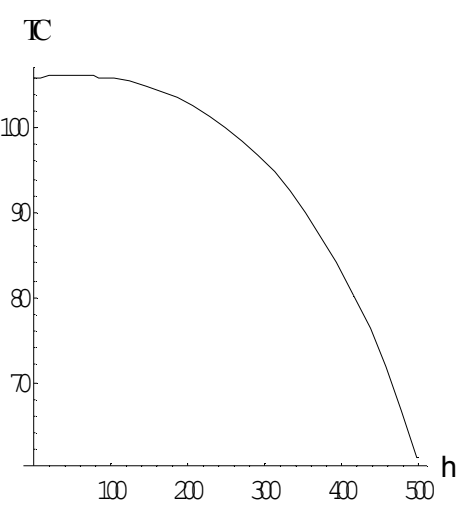

Fig 7.(b) The effect of parameter $\eta$ on the total cost in the fuzzy model

Fig. 8(a) and Fig. 8(b) show the effect of $n$ (number of deliveries) on the total cost of the model in the crisp and fuzzy model. As we increase the $n$ then total cost decreases up to a point and then it again increases. Therefore, we have to take an optimal value of the number of cycles to minimize the total cost. 


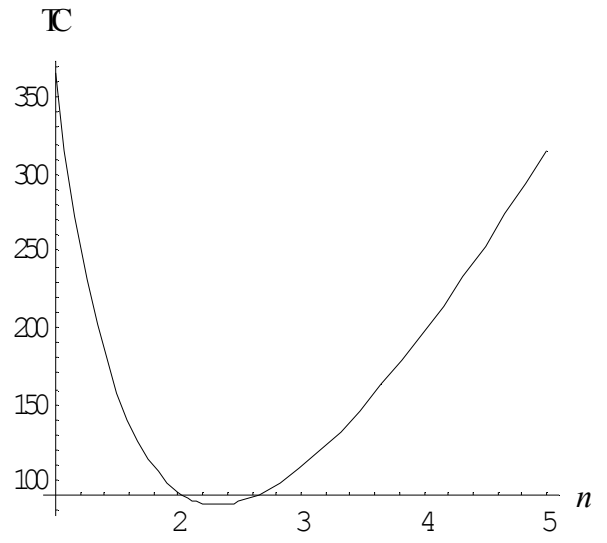

Fig 8.(a) The effect of parameter $n$ on the total cost in the crisp model

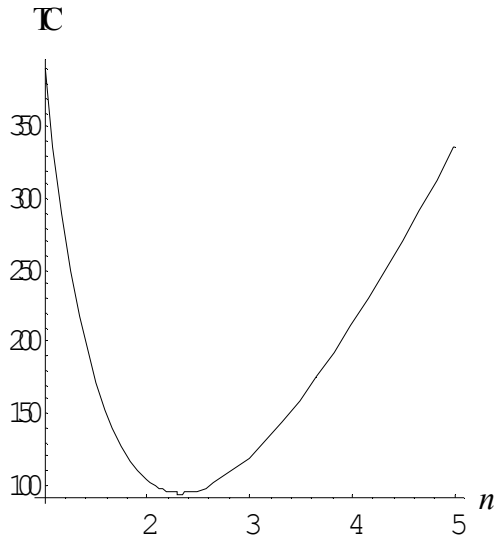

Fig 8.(b) The effect of parameter $n$ on the total cost in the fuzzy model

According to Fig. 9(a) and 9(b), as $r$ (inflation rate) increases the total cost increases in crisp and fuzzy model both.

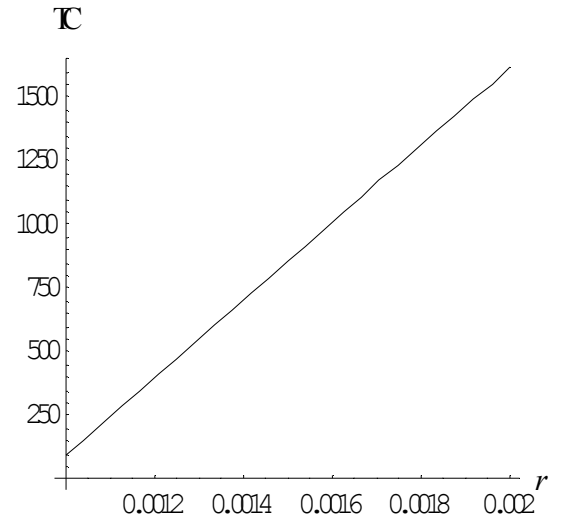

Fig. 9. (a) The effect of parameter $r$ on the total cost in the crisp model

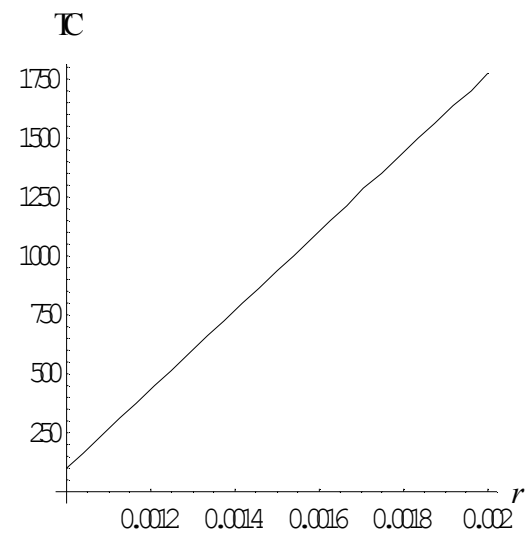

The following inferences can be observed from the sensitivity analysis based on Table 1 .

1) The total cost per unit time is less sensitive on the changes in set up cost parameter.

2) The holding cost and purchasing cost has stronger effect on the optimal value of total cost than the other parameters.

3) In the fuzzy sense, optimal production time and supplier's time period is lower than the time period obtained in the crisp model.

4) Total cost obtained in the fuzzy sense is higher than the crisp total cost. 
Table 1

Sensitivty analysis of the proposed model

\begin{tabular}{llccccc}
\hline Parameters & & \multicolumn{4}{c}{ Percentage of under-estimation and over-estimation parameters } \\
\cline { 2 - 6 } & & -50 & -20 & 0 & +20 & +50 \\
\hline $\mathrm{h}_{\mathrm{p}}$ & $\mathrm{T}_{1}$ & 8.39818 & 8.33003 & 8.2854 & 8.24164 & 8.17714 \\
& $\mathrm{~T}_{3}$ & 3.33672 & 3.31126 & 3.29462 & 3.27824 & 3.25414 \\
& $\mathrm{TC}$ & 163.104 & 120.853 & 92.678 & 64.4959 & 22.2102 \\
\hline $\mathrm{c}_{\mathrm{p}}$ & $\mathrm{T}_{1}$ & 8.285635 & 8.2855 & 8.2854 & 8.28543 & 8.28534 \\
& $\mathrm{~T}_{3}$ & 3.2946 & 3.2946 & 3.29462 & 3.2946 & 3.29457 \\
& $\mathrm{TC}$ & 71.2539 & 84.1083 & 92.678 & 101.248 & 114.102 \\
\hline $\mathrm{A}_{\mathrm{p}}$ & $\mathrm{T}_{1}$ & 8.28507 & 8.28532 & 8.2854 & 8.28565 & 8.28590 \\
& $\mathrm{~T}_{3}$ & 3.29447 & 3.29456 & 3.29462 & 3.29468 & 3.29478 \\
& $\mathrm{TC}$ & 92.666 & 92.6732 & 92.678 & 92.6828 & 92.69 \\
\hline $\mathrm{h}_{\mathrm{s}}$ & $\mathrm{T}_{1}$ & 10.6858 & 8.96774 & 8.2854 & 7.78765 & 7.24681 \\
& $\mathrm{~T}_{3}$ & 4.80537 & 3.74045 & 3.29462 & 2.95779 & 2.57807 \\
& $\mathrm{TC}$ & 33.2215 & 72.3353 & 92.678 & 109.935 & 131.577 \\
\hline $\mathrm{c}_{\mathrm{s}}$ & $\mathrm{T}_{1}$ & 8.32514 & 8.3039 & 8.2854 & 8.26368 & 8.22452 \\
& $\mathrm{~T}_{3}$ & 3.21619 & 3.26421 & 3.29462 & 3.32375 & 3.36501 \\
& $\mathrm{TC}$ & 113.308 & 101.001 & 92.678 & 84.2597 & 71.452 \\
\hline $\mathrm{A}_{\mathrm{s}}$ & $\mathrm{T}_{1}$ & 8.2834 & 8.28466 & 8.2854 & 8.28633 & 8.28754 \\
& $\mathrm{~T}_{3}$ & 3.29384 & 3.29431 & 3.29462 & 3.29493 & 3.2954 \\
& $\mathrm{TC}$ & 92.6181 & 92.6541 & 92.678 & 92.7019 & 92.7378 \\
\hline $\mathrm{c}_{\mathrm{s} 1}$ & $\mathrm{~T}_{1}$ & 8.30627 & 8.29371 & 8.2854 & 8.2774 & 8.26549 \\
& $\mathrm{~T}_{3}$ & 3.28856 & 3.29222 & 3.29462 & 3.29699 & 3.30049 \\
& $\mathrm{TC}$ & 92.2668 & 92.5152 & 92.678 & 92.8386 & 93.0753 \\
\hline $\mathrm{c}_{\mathrm{s} 2}$ & $\mathrm{~T}_{1}$ & 9.13466 & 8.51449 & 8.2854 & 8.12562 & 7.95948 \\
& $\mathrm{~T}_{3}$ & 3.06456 & 3.22907 & 3.29462 & 3.34207 & 3.39294 \\
& $\mathrm{TC}$ & 77.1776 & 88.2402 & 92.678 & 95.9005 & 99.3641 \\
\hline & & & & & &
\end{tabular}

\section{Concluding Remarks}

In this paper, we have investigated a model where producer and supplier use the PT to reduce the deterioration rate. This model is analyzed under two circumstances of the crisp and the fuzzy forms. Here, production and demand is treated as a fuzzy variable. Producer and supplier have different PT cost, which depends on the type of technology used. A solution procedure is also derived to optimize the total cost of producer and supplier. The main emphasis of this paper is on cost reduction by making effective investment in PT. Sensitivity analysis shows that while PT applies in the model, then the total cost is reduced due to the decrement in the deterioration rate. These changes can also be seen in the fuzzy sense but total cost is slightly higher than the crisp model. Effect of cost parameters on the total cost is also analyzed. Finally, the proposed model can be extended in several ways. For example, we could extent the model to allow for multi supplier.

\section{Acknowledgment}

The authors wish to thank the referees for their constructive comments and suggestions on the earlier version of the paper. 


\section{References}

Bhunia, A.K., Kundu, S., Sannigrahi, T. and Goyal, S.K. (2009). An application of tournament genetic algorithm in a marketing oriented economic production lot-size model for deteriorating items. International Journal of Production Economics, 119(1) 112-121.

Chang, S.C., Yao, J.S. and Lee, H.M. (1998). Economic reorder point for fuzzy backorder quantity. European Journal of Operational Research, 109(1) 183-202.

Chang, H.J. and Lin, W.F. (2010). A partial backlogging inventory model for non-instantaneous deteriorating items with stock-dependent consumption rate under inflation. Yugoslav Journal of Operation Research, 20(1) 35-54.

Chang, C.T., Teng, J.T. and Goyal, S.K. (2010). Optimal replenishment policies for non- instantaneous deteriorating items with stock-dependent demand. International Journal of Production Economics, 123(1) 62-68.

Covert, R.P. and Philip, G.C. (1973). An EOQ model for items with Weibull distribution deterioration. AIIE Transaction, 5(4) 323-326.

Ghare, P.M. and Schrader, G.F. (1963). A model for exponential decaying inventory. Journal of Industrial Engineering, 14(6) 238-43.

Goyal, S.K. and Giri, B.C. (2001). Recent Trends in Modeling of Deteriorating Inventory. European Journal of Operational Research, 134(1) 1-16.

Dave, U. and Patel, L.K. (1981). (T, Si) policy inventory model for deteriorating items with time proportional demand. Journal of the Operational Research Society, 32(1) 137-142.

Dye, C.Y. and Hsieh, T.P. (2012). An optimal replenishment policy for deteriorating items with effective investment in Preservation Technology. European Journal of Operational Research, 218(1), 106-112.

Dye, C.Y. (2013). The effect of Preservation Technology investment on a non- instantaneous deteriorating inventory model. Omega, 41(1) 872-880.

Dutta, D. and Kumar, P. (2013). Fuzzy inventory models for deteriorating items with shortages and fully backlogged condition. International Journal of Soft Computing and Engineering, 3(2), 393398.

Huang, Y.H., Wang, C.C., Huang, C.J. and Dye, C.Y. (2011). Comments on preservation technology investment for deteriorating inventory. African Journal of Business Management., 5(11) 4636-4643.

Hsieh, T.P. and Dye, C.Y. (2013). A production inventory model incorporating the effect of preservation technology investment when demand is fluctuating with time. Journal of Computational and Applied Mathematics, 239, 25-36.

Johnny, C.H., Adriano, O.S. and Chang, Y.L. (2007). An evaluation of lot-sizing heuristics for deteriorating inventory in material requirements planning systems. Computers and Operations Research, 34(9) 2562-2575.

Kang, S. and Kim, I. (1983). A study on the price and production level of the deteriorating inventory system. International Journal of Production Research, 21(6) 449-460.

Lin, D.C. and Yao, J.S. (2000). Fuzzy economic production for production inventory. Fuzzy Sets and Systems, 111(1) 465-495.

Murr, D.P. and Morris, L.L. (1975). Effect of storage temperature on post change in mushrooms. Journal of the American Society for Horticultural Science, 100(1) 16-19.

Ouyang, L.Y., Wu, K.S. and Yang, C.T. (2006). A study on an inventory model for non- instantaneous deteriorating items with permissible delay in payments. Computers and Industrial Engineering, 51(4) 637-651.

Papachristos, S. and Skouri, K. (2000). An optimal replenishment policy for deteriorating items with time-varying demand and partial-exponential type-backlogging. Operations Research Letters, 27(4) $175-184$.

Ruoning, X. and Xiaoyan, Z. (2010). Analysis of supply chain coordination under fuzzy demand in a two-stage supply chain. Applied Mathematical Modeling, 34(1) 129-139. 
San José, L.A., Sicilia, J. and García-Laguna, J. (2006). Analysis of an inventory system with exponential partial backordering. International Journal of Production Economics, 100(1) 76-86.

Singh, S.R. and Singh, C. (2008). Fuzzy inventory model for finite rate of replenishment using signed distance method. International Transactions in Mathematical Sciences and Computer, 1(1) 21-30.

Singh, S.R., Kumari, R. and Kumar, N. (2011). Optimization of fuzzy inventory model for differential items. International Journal of Operational Research, 11(3) 290-315.

Singh, C. and Singh, S.R. (2011). Imperfect production process with exponential demand rate, Weibull deterioration under inflation. International Journal of Operational Research, 12(4) 430-445.

Teng, J.T., Yang, H.L. and Ouyang, L.Y. (2003). On an EOQ model for deteriorating items with timevarying demand and partial backlogging. Journal of the Operational Research Society , 54(4) $432-$ 436.

Teng, J.T. and Yang, H.L. (2004). Deterministic economic order quantity models with partial backlogging when demand and cost are fluctuating with time. Journal of the Operational Research Society, 55(5) 495-503.

Urvashi and Singh, S. R. (2013). Inventory Control with fuzzy inflation and volume flexibility under random planning horizon. International Journal of Computer Applications, 76(11), 8-17.

Wee, H.M., Teng, H.M. and Hsu, P.H. (2010). Preservation technology investment for deteriorating inventory. International Journal of Production Economics, 124(2) 388-394.

Yadav, D., Singh, S. R. and Kumari, R. (2013). Retailer's optimal policy under inflation in fuzzy environment with trade credit. International Journal of Systems Science, 1-9.

Yang, P.C. and Wee, H.M. (2006). A collaborative inventory system with permissible delay in payment for deteriorating items. Mathematical and Computer Modeling, 43(3-4) 209-221. 